\title{
ИММУННЫЙ СТАТУС ТЕЛЯТ-ПОТОМКОВ БЫКОВ-ПРОИЗВОДИТЕЛЕЙ ЗАРУБЕЖНОЙ СЕЛЕКЦИИ И ОТЕЧЕСТВЕННЫХ ПЛЕМЕННЫХ ЗАВОДОВ
}

Г. И. Боряев, доктор биол. наук, профрессор; Ю. С. Гончарук, аспирант;

Е. В. Здоровьева, канд. биол. наук, доцент; А. В. Носов, канд. экон. наук, доцент;

Ю. Н. Федоров*, доктор биол. наук, профессор;

Е. К. Кистанова* , канд. биол. наук, доцент

Федеральное государственное бюджетное образовательное учреждение высшего образования «Пензенский государственный аграрный университет», Россия, т. 8(8412) 628151, e-mail: boruev@yandex.ru;

*Федеральное государственное бюджетное научное учреждение «Всероссийский научно-исследовательский и технологический институт биологической промышленности», e-mail: boryaev.g.i@pgau.ru;

**Институт биологии и иммунологии размножения при Болгарской Академии Наук, Болгария, e-mail: kistanova@gmail.com

Племенные быки вносят в популяцию основой вклад генетического прогресса, поэтому оценка иммунологического статуса их потомков позволит дополнить характеристику племенных качеств быков-производителей и разработать способы повышения естественной резистентности молодняка животных. Результаты исследований позволяют утверждать, что у потомков зарубежных быков-производителей выявлено снижение гуморального звена иммунной системы по сравнению с потомками, полученными от быков-производителей отечественных племенных заводов и зарубежных быков, завезенных в Россию в восьми месячном возрасте. Наблюдаемое снижение выразилось в пониженном уровне иммуноглобулинов G-класса на $40 \%$, М-класса в 5 раз и IgA на $60 \%$, а также в уменьшении количества Tлимфоцитов в крови телят.

Ключевые слова: высокопродуктивные животные, быки-производители, отечественная селекция, зарубежная селекция, телята, иммунный статус.

\section{Введение}

Использование мирового генофонда крупного рогатого скота позволяет значительно улучшить продуктивные качества животных. Однако, необходимо учитывать способность животных, особенно молодняка, к условиям интенсивных технологий при постановке задачи сохранения приспособленности животных к традиционным кормовым и природно-климатическим условиям разных регионов нашей страны [3-5, 7 , $9,12,15]$.

Практика животноводства свидетельствует, что скот импортных молочных пород часто уступает местному скоту в плодовитости, усвояемости применяемых на наших фермах и комплексах, кормов, в устойчивости к некоторым инфекционным заболеваниям, в приспособляемости к экстремальным природно-климатическим условиям, что, безусловно, сказывается на получаемом потомстве. Поэтому целью наших исследований явилось изучение иммунного статуса организма телят, полученных от быков-производителей зарубежной селекции и быков, выращенных на отечественных племенных заводах $[1,2,6$, $8,10,11,13,14,16-18]$.

\section{Методы и материалы}

Базой для проведения исследований иммунного статуса телят являлись пять хозяйств производителей молока Пензенской области и одно предприятие Нижегородской области. Предприятия используют семя быков-производителей как зарубежной, так и отечественной селекции. Из шести предприятий, участвовавших в исследованиях, два предприятия используют для осеменения молочных коров семя быков-производителей отечественных племенных заводов.

Для изучения иммунного статуса телят были отобраны потомки следующих быковпроизводителей: 011HO11565 - AltaPADLOCK, 011HO11596 - AltaNEWMAN, 011HO11174 - AltalGOR, относящихся к линии Wisldeal. Быки-производители 011Н011648 - Alta DGATE, 011HO11283 - AltaMERCI n 011HO11000 - AltaSAMOA относятся к линии Reflection Sovereign.

На предприятии Нижегородской области используют семя быков канадской 


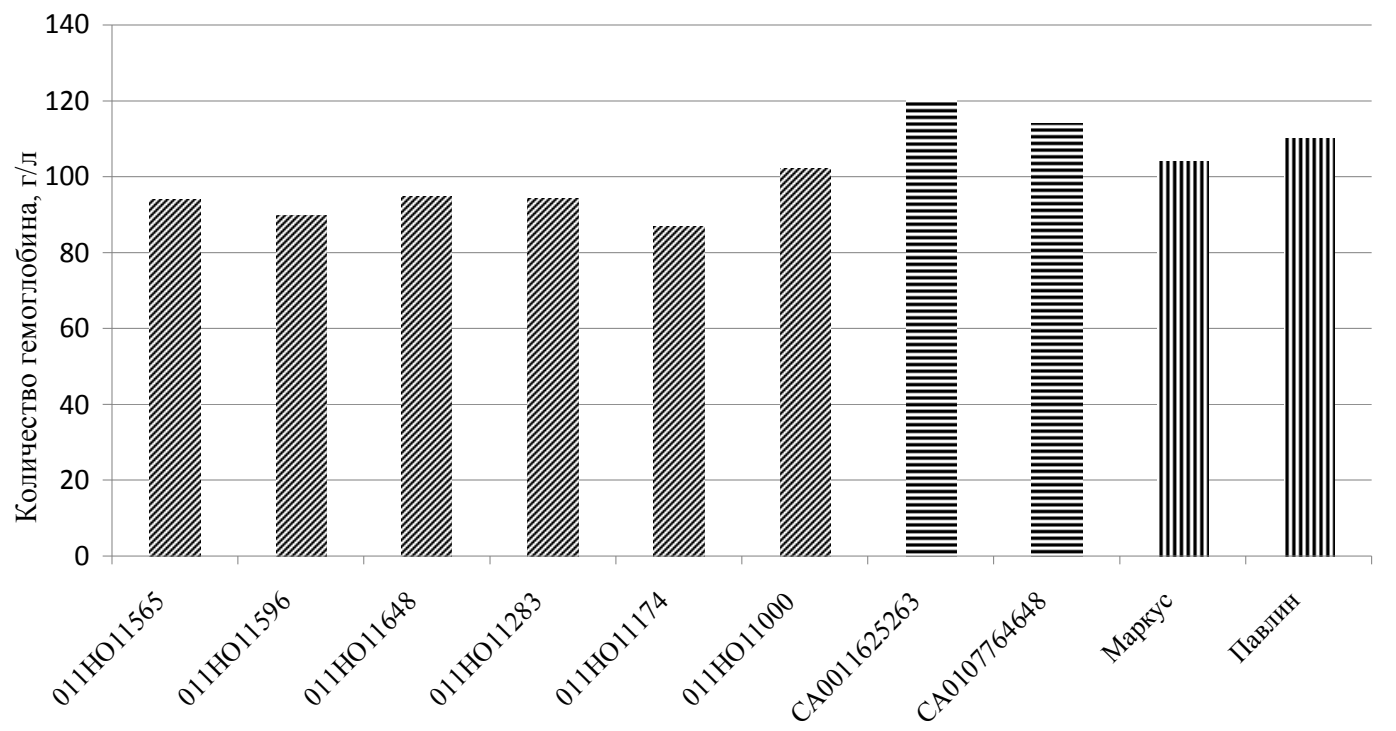

Быки-производители

Уровень гемоглобина в крови телят, полученных от быков-производителей:

"W/и - быки-производители зарубежной селекции;

全 - быки-производители зарубежной селекции, адаптированные в России;

IIIII - быки-производители отечественных племенных заводов

селекции СА0011625263, СА0107764648, которые в восьми месячном возрасте были завезены в Россию и содержаться в условиях ООО «Нижегородское» по племенной работе. Бык-производитель СА0011625263 относится к линии Леирд, бык СА0107764648 - Reflection Sovereign 198998

Быки-производители отечественной селекции были представлены быками 4862 Маркус (рожденный АО ПЗ Гражданский Приозерский район Ленинградская область) и 165 Павлин (рожденный в ЗАО ПЗ Волосовский район Ленинградской области). Бык 4862 Маркус принадлежит к линии Wisldeal, бык 165 Павлин - Reflection Sovereign 198998.

Для оценки иммунного статуса молодняка от каждого быка-производителя было отобрано по 20 потомков, у которых из яремной вены отбиралась кровь для исследований. Определяли концентрацию иммуноглобулинов G-, М- и А- классов в сыворотке крови телят, количество Тлимфоцитов в крови, лейкограмму, количество лейкоцитов, количество эритроцитов, количество тромбоцитов в 1 л крови, содержание гемоглобина.

Для определения уровня иммуноглобулинов в сыворотке крови применялся метод простой радиальной иммунодифффузии с использованием моноспецифических антисывороток, предоставленных членомкорреспондентом РАН Ю. Н. Федоровым. Гематологические показатели и лейкограмму определяли с помощью автоматического гематологического ветеринарного анализатора BC-2800Vet.

\section{Результаты}

Результаты исследований гематологических показателей телят, полученных от быков-производителей как зарубежной, так и отечественной селекции, свидетельствует о хорошем состоянии организма животных. Bсе параметры находятся в пределах фризиологической нормы.

Анализируя данные, полученные в ходе проведения исследований, можно отметить, что уровень гемоглобина у всех телят находится в пределах рефрератных значений и колеблется от 90 до 120 г/л. Наибольшая концентрация гемоглобина установлена у телят в хозяйстве Нижегородской области. У телят, полученных от быков-производителей зарубежной селекции, адаптированных в России, уровень данного показателя составлял $120 \pm 3,18$ г/л и $114 \pm 3,52$ г/л., соответственно.

Проводя сравнительный анализ уровня гемоглобина у телят - потомков зарубежных быков-производителей и быков отечественных племенных заводов можно ут- 
Таблица 2

Уровень Т-лимфоцитов в крови телят-потомков зарубежных и отечественных быков

\begin{tabular}{|l|c|c|}
\hline \multicolumn{1}{|c|}{ Бык-производитель } & Т-лимфоцитов, ${ }^{*} 10^{9} / \mathrm{L}$ & Т-лимфоциты, $\%$ \\
\hline $011 \mathrm{HO} 11565$ - AltaPADLOCK & $0,410 \pm 0,069$ & $26,1 \pm 1,51$ \\
\hline $011 \mathrm{HO} 11596$-AltaNEWMAN & $0,635 \pm 0,176$ & $27,8 \pm 1,45$ \\
\hline $011 \mathrm{HO} 11648$ - AltaDGATE & $0,366 \pm 0,070$ & $25,7 \pm 1,56$ \\
\hline $011 \mathrm{HO} 11283$ - AltaMERCI & $0,755 \pm 0,110$ & $26,6 \pm 1,23$ \\
\hline $011 \mathrm{HO} 11174$ - AltaIGOR & $1,00 \pm 0,141$ & $24,3 \pm 1,62$ \\
\hline $011 \mathrm{HO} 11000$ - AltaSAMOA & $1,39 \pm 0,170$ & $28 \pm 1,22$ \\
\hline CA0011625263 & $1,67 \pm 0,509$ & $29,1 \pm 1,97$ \\
\hline CA0107764648 & $1,08 \pm 0,150$ & $26,1 \pm 1,17$ \\
\hline Маркус & $0,65 \pm 0,067$ & $30,8 \pm 1,84$ \\
\hline Павлин & $0,72 \pm 0,087$ & $32,4 \pm 1,55$ \\
\hline
\end{tabular}

верждать, что у потомков отечественных быков содержание гемоглобина в крови выше, чем у телят, полученных от быков зарубежной селекции.

В результате исследований выявлены существенные различия в показателях гуморального звена иммунитета у потомков зарубежных и отечественных быков. У телят, полученных от быков зарубежной селекции, содержание иммуноглобулинов Gкласса находится на нижней границе физиологической нормы и соответствует 12,65 мг/мл. У потомков быков-производителей отечественных племенных заводов среднее значение составило 18,0 мг/мл. Из шести зарубежных быков лишь у потомков быка 011НО11000 концентрация IgG в сыворотке крови выше 20 мг/мл. Аналогичная картина наблюдалась по отношению к иммуноглобулинам М- и А-классов.

Т-лимфоцитам крови принадлежит ведущая роль в формировании иммунитета. Активация лимфоцитов представляет собой сложный биохимический процесс, связанный с распознаванием антигена, и происходит непосредственно с участием имеющихся на мембранах лимфоцитов специфических антигенных рецепторов. Большинство Т-лимфоцитов несут на мембране клеточный рецептор, состоящий из альфаи бета-цепей. Такие лимфоциты принято

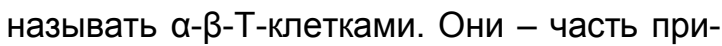
обретенной иммунной системы.

Исследование количества Т-лимфоцитов в крови телят представлены в таблице 2.

Установлено, что наивысший уровень Т-лимфоцитов имеют потомки быка канадской селекции, адаптированного к российским условиям CA0011625263, и потомки быка 011НO11000 - AltaSAMOA.

В среднем количество Т-лимфоцитов у телят, полученных от быков отечественной селекции находится на уровне $0,685^{*} 10^{9} / \mathrm{L}$, уровень аналогичного параметра у потомков быков производителей зарубежной селекции составил $0,753^{*} 10^{9} / \mathrm{L}$, а в крови потомков быков-производителей, адаптированных к местным условиям $-1,375^{*} 10^{9} / \mathrm{L}$.

Заключение. Таким образом, полученные экспериментальные данные свидетельствуют о том, что гематологические показатели телят, полученных от быковпроизводителей как зарубежной, так и отечественной селекции, находятся в пределах фризиологической нормы. Однако, у потомков отечественных быков содержание гемоглобина в крови выше, чем у телят, полученных от быков зарубежной селекции, на $12 \%$. Выявлены существенные различия в показателях гуморального звена иммунитета у потомков зарубежных и отечественных быков. У телят, полученных

Уровень иммуноглобулинов телят - потомков быков

Таблица 1 зарубежной и отечественной селекции

\begin{tabular}{|c|c|c|c|}
\hline Бык-производитель & IgG, мг/Мл & IgM, мг/мл & $\lg \mathrm{A}, \mathrm{мг/МЛ}$ \\
\hline 011HO11596 - AltaNEWMAN & $12,04 \pm 1,14$ & $0,403 \pm 0,013$ & $0,129 \pm 0,0182$ \\
\hline 011HO11283 - AltaMERCI & $11,32 \pm 0,861$ & $0,421 \pm 0,025$ & $0,115 \pm 0,008$ \\
\hline 011HO11565 - AltaPADLOCK & $11,10 \pm 0,874$ & $0,401 \pm 0,013$ & $0,129 \pm 0,012$ \\
\hline 011HO11648 - AltaDGATE & $10,37 \pm 0,744$ & $0,371 \pm 0,009$ & $0,154 \pm 0,011$ \\
\hline 011HO11174 - AltalGOR & $9,97 \pm 1,34$ & $1,38 \pm 0,093$ & $0,138 \pm 0,009$ \\
\hline 011HO11000 - AltaSAMOA & $21,14 \pm 2,78$ & $0,839 \pm 0,074$ & $0,808 \pm 0,164$ \\
\hline CA0011625263 & $20,65 \pm 2,71$ & $1,46 \pm 0,221$ & $0,202 \pm 0,011$ \\
\hline CA0107764648 & $15,90 \pm 1,92$ & $1,45 \pm 0,142$ & $0,180 \pm 0,011$ \\
\hline Маркус & $17,03 \pm 1,67$ & $2,75 \pm 0,499$ & $0,581 \pm 0,109$ \\
\hline Павлин & $18,24 \pm 1,84$ & $2,97 \pm 0,527$ & $0,624 \pm 0,197$ \\
\hline
\end{tabular}

Нива Поволжья $\quad$ № 4 (53) ноябрь 2019 
от быков зарубежной селекции, содержание иммуноглобулинов G-класса находится на нижней границе физиологической нормы, что соответствует легкому иммунодефициту. У потомков быков-производителей отечественных племенных заводов сред- нее значение составило 18,0 мг/мл. Аналогичная картина наблюдалась по отношению к иммуноглобулинам М- и А-классов. Высокий уровень Т-лифоцитов имеют потомки быков канадской селекции, адаптированных к российским условиям.

\section{Лumepamypa}

1. Алагирова, Ж. Т. Адаптивные способности голштинского скота отечественной и американской селекции при их интродукции в Кабардино-балкарскую республику: автореферат диссертации кандидата биолиологических наук: 06.02.07. / Ж. Т. Алагирова. - Дубровицы, 2016. - 19 с.

2. Альтергот, В. В. Технология эксплуатации импортных коров голштинской породы в условиях Самарской области / В. В. Альтергот, Х. Б. Баймишев // Известия Самарской ГСХА. - 2011. № 1. - С. 116-119.

3. Барашкин, М.И. Оценка и коррекция иммунометаболических показателей у коров при адаптации к промышленным технологиям содержания с учетом эпизоотического состояния: авторефрерат диссертации доктора ветеринарных наук: 06.02 .02 / М. И. Барашкин. - Екатеринбург, 2014. - 39 c.

4. Богатырева, И. А. Оценка роста, гематологического статуса и поведения телок симментальской породы разной селекции / И. А. Богатырева, Д. Р. Смакуев // Вестник Алтайского государственного аграрного университета. - 2015. - № 7 (129). - С. 102-107.

5. Брагинец, С. А. Молочная продуктивность и продолжительность хозяйственного использования коров в зависимости от происхождения отцов / С. А. Брагинец, А. Ю. Алексеева //Агрономия, ветеринария и зоотехния. - 2012. - № 5. - С. 67-72.

6. Григорьев, В. С. Естественная резистентность коров голштинской породы разных генераций / В. С. Григорьев, В. С. Карамаев // Ветеринарная медицина XXI века: инновации, опыт, проблемы и пути их решения: Материалы международной научно-практической конференции. - Ульяновск: Ульяновская ГСХА, 2011. - Т. 2. - С. 171-174.

7. Карамаева, А. С. Показатели естественной резистентности коров разных пород / А. С. Карамаева, В. В. Зайцев // Известия НВ АУК. - 2011. - № 1. - С. 150-153.

8. Комбарова, Н. Диспансеризация быков-производителей по состоянию иммунной системы и биохимии крови / Н. Комбарова, А. Абилов // Молочное и мясное скотоводство. - 2009. - № 3. C. $30-32$.

9. Коровин, А. В. Адаптационные и продуктивные особенности коров молочных пород в условиях промышленного комплекса: дисертация кандидата сельскохозяйственных наук: 06.02.01. I А. В. Коровин. - Кинель, 2015. - 194 с.

10. Мохов, Б. П. Продуктивность и состояние резистентности импортных и местных первотелок / Б. П. Мохов, Е. П. Савельева // Зоотехния. - 2010. - № 6. - С. 9-10.

11. Никулин, И. А. Биохимический статус коров отечественной и импортной селекции в условия Воронежской области / И. А. Никулин, О. А. Ратных, Ж. А. Ветрова // Биология в сельском хозяйстве. - 2017. - № 3 (16), - С. 10-14.

12. Сулыга, Н. В. Продуктивные качества коров-первотелок голштинской черно-пестрой породы венгерской селекции в адаптационный период / Н. В. Сулыга, Г. П. Ковалева // Зоотехния. 2010. - № 2. - C. 4-6.

13. Таирова, А. Р. Особенности белкового метаболизма в организме коров симментальской породы австрийской селекции в условиях агроэкосистемы Южного Урала / А. Р. Таирова, Л. Г. Мухамедьярова // Известия Оренбургского ГАУ. - 2011. - № 1 (29). - С. 83-84.

14. Федоров, Ю. Н. Методы оценки иммунного статуса новорожденных телят // Инновации в интенсификации производства и переработки сельскохозяйственной продукции: Материалы Международной научно-практической конференции / Ю. Н. Федоров, В. И. Клюкина, О. А. Богомолова. -Волгоград: Сфрера, 2015. - С. 8-14.

15. Иммунный статус сельскохозяйственных животных в зависимости от продуктивности, сезона года, фризиологического состояния и генотипа / И. А. Шкуратова, А. Г. Исаева, Я. Б. Бейкин, А. С. Кривоногова // Ветеринария Кубани. - 2013. - № 2. - С. 23-25.

16. Bollwein, H. Declining fertility due to high yield? / H. Bollwein // EuroFier innovatins (Germany) - 2010. - P. 20-22.

17. Halleran, J. Apparent efficiency of colostral immunoglobulin $\mathrm{G}$ absorption in Holstein heifers / J. Halleran, HJ. Sylvester, DM. Foster // J Dairy Science. - 2017. - № 100 (4). - P. 3282-3286.

18. Prusinowska, I. Estimation of chosen blood diagnostic indices in imported cows and their progeny / I. Prusinowska, K. Iwańczuk-Czernik, A. Wójcik. Animal Feed Science. -2002. - № 11 (2). P. 255-263. 
UDC 636.082.12+612.017.1

DOI: 10.36461/NP.2019.52.3.017

\section{IMMUNE STATUS OF OFFSPRING CALVES OF SERVICING BULLS OF FOREIGN BREEDING AND DOMESTIC STUD FARMS}

G. I. Boryaev, Doctor of Biological Sciences, Professor; Yu. S. Goncharuk, postgraduate student;

E. V. Zdorovyeva, Candidate of Biological Sciences, Assistant-professor; A. V. Nosov, Candidate

of Economic Sciences, Assistant-professorm; Yu. N. Fyodorov*, Doctor of Biological Sciences,

Professor; Ye. K. Kistanova**, Candidate of Biological Sciences, Assistant-professor

Federal State Budgetary Educational Institution of Higher Education «Penza State Agrarian University», Russia, T. 8(8412) 628151, e-mail: boruev@yandex.ru;

*Federal State Budget Scientific Institution «All-Russian Scientific Research and Technological Institute of Biological Industry», e-mail: boryaev.g.i@pgau.ru;

${ }^{* *}$ Institute of Biology and Immunology of Reproduction of Bulgarian Academy of Sciences,

Bulgaria, e-mail: kistanova@gmail.com

Pedigree bulls make the contribution of genetic progress to the population, therefore, an assessment of the immunological status of their offspring will add the characteristics of the breeding qualities of bulls and develop ways to increase the congenital immunity of young animals. The results of the studies suggest that the offspring of foreign cervicing bulls has a decrease in the humoral link of the immune system compared to the offspring obtained from bulls of domestic stud farms and foreign bulls brought to Russia at eight months of age. The observed decrease was expressed in a reduced level of G-class immunoglobulins by $40 \%$, of M-class - by 5 times and of IgA - by $60 \%$, as well as in a decrease in the number of T-lymphocytes in the blood of calves.

Key words: highly productive animals, servicing bulls, domestic breeding, foreign breeding, calves, immune status

\section{References:}

1. Alagirova, Zh. T. Adaptive abilities of Holstein cattle of domestic and American selection upon their introduction into the Kabardino-Balkarian Republic: abstract of the dissertation of the candidate of biological sciences: 06.02.07. / Zh. T. Alagirova. - Dubrovitsy, 2016.-- 19 p.

2. Altergot, V. V. The technology of exploitation of imported cows of the Holstein breed in the conditions of the Samara region / V. V. Altergot, H. B. Baimishev // Bulletin of Samara State Agricultural Academy. - 2011. - No. 1. - p. 116-119.

3. Barashkin, M. I. Evaluation and correction of immunometabolic indicators in cows when adapting to industrial technologies of keeping, taking into account the epizootic state: abstract of the dissertation of the doctor of veterinary sciences: 06.02.02 / M. I. Barashkin. - Ekaterinburg, 2014.-- $39 \mathrm{p}$.

4. Bogatyreva, I. A. Assessment of growth, hematological status and behavior of heifers of Simmental breed of different breeding / I. A. Bogatyreva, D. R. Smakuev // Bulletin of Altai State Agrarian University. - 2015. - No. 7 (129). - p. 102-107.

5. Braginets, S. A. Dairy productivity and the duration of the economic use of cows, depending on the origin of the fathers / S. A. Braginets, A. Yu. Alekseeva // Agronomy, veterinary medicine and livestock. - 2012. - No. 5. - p. 67-72.

6. Grigoriev, V. S. Natural resistance of Holstein cows of different generations / V. S. Grigoriev, V. S. Karamaev // Veterinary medicine of the XXI century: innovations, experience, problems and solutions: Materials of an international scientific and practical conference. - Ulyanovsk: Ulyanovsk State Agricultural Academy, 2011.-- V. 2.-- p. 171-174.

7. Karamaeva, A. S. Indices of congenital immunity of cows of different breeds / A. S. Karamaeva, V. V. Zaitsev // Proceedings of NV AUK. - 2011. - No. 1. - p. 150-153.

8. Kombarova, N. Clinical examination of bulls according to the state of the immune system and blood biochemistry / N. Kombarova, A. Abilov // Dairy and beef cattle farming. - 2009. - No. 3. - p. 30-32.

9. Korovin, A. V. Adaptive and productive features of dairy cows in an industrial complex: Ph. D. dissertation: 06.02.01. / A. V. Korovin. - Kinel, 2015.-- 194 p.

10. Mokhov, B.P. Productivity and resistance status of imported and domestic heifers / B. P. Mokhov, E. P. Saveliev // Zootechniya. - 2010. - No. 6. - p. 9-10.

11. Nikulin, I. A. The biochemical status of cows of domestic and foreign selection in the conditions of the Voronezh region / I. A. Nikulin, O. A. Ratnykh, J. A. Vetrova // Biologiya v selskom khozyaistve. 2017. - No. 3 (16), - p. 10-14.

12. Sulyga, N. V. Productive qualities of first-calf cows of the Holstein black-motley breed of Hungarian selection in the adaptation period / N. V. Suliga, G. P. Kovaleva // Zootechniya. - 2010. No. 2. - p. 4-6. 
13. Tairova, A. R. Features of protein metabolism in the body of cows of the Simmental breed of Austrian selection under the agroecosystem of the South Urals / A. R. Tairova, L. G. Mukhamedyarov // Bulletin of Orenburg State Agrarian University. - 2011. - No. 1 (29). - P. 83-84.

14. Fedorov, Yu. N. Methods for assessing the immune status of newborn calves // Innovations in the intensification of production and processing of agricultural products: Materials of the International scientific-practical conference / Yu. N. Fedorov, V. I. Klyukina, O. A. Bogomolova. -Volgograd: Sphere, 2015. - p. 8-14.

15. The immune status of farm animals depending on productivity, season, physiological condition and genotype / I. A. Shkuratova, A. G. Isaeva, Ya. B. Beikin, A. S. Krivonogova // Veterinary of the Kuban. - 2013. - No. 2. - p. 23-25.

16. Bollwein, H. Declining fertility due to high yield? / H. Bollwein // EuroFier innovatins (Germany). - 2010. - P. 20-22.

17. Halleran, J. Apparent efficiency of colostral immunoglobulin $\mathrm{G}$ absorption in Holstein heifers / J. Halleran, HJ. Sylvester, DM. Foster // J Dairy Science. - 2017. - № 100 (4). - P. 3282-3286.

18. Prusinowska, I. Estimation of chosen blood diagnostic indices in imported cows and their progeny / I. Prusinowska, K. Iwańczuk-Czernik, A. Wójcik. Animal Feed Science. -2002. - № 11 (2). P. 255-263. 